\title{
Young patients with risk factors prevalent in the elderly - differences in comorbidity depending on severity of psoriasis: a nationwide cross-sectional study in Swedish health registers
}

This article was published in the following Dove Press journal: Clinical Epidemiology

\author{
Mohammadhossein \\ Hajiebrahimi ${ }^{1,2}$ \\ Marie Linder' \\ David Hägg' \\ Ina Anveden Berglind' \\ Sean McElligott ${ }^{3}$ \\ Valgard Sverrir Valgardsson ${ }^{4}$ \\ Reginald Villacorta ${ }^{3}$ \\ Anders Sundström' \\ 'Center for Pharmacoepidemiology, \\ Department of Medicine, Karolinska \\ Institutet, Stockholm, Sweden; \\ ${ }^{2}$ Statistics and Epidemiology Unit, \\ Health Faculty, Golestan University \\ of Medical Sciences, Gorgan, Iran; \\ ${ }^{3} J a n s s e n$ Research and Development, \\ LLC, Horsham, PA, USA; ${ }^{4}$ Janssen-Cilag \\ AS, Oslo, Norway
}

\begin{abstract}
Background: Association between psoriasis severity and cerebro- and cardiovascular comorbidities has rarely been investigated.

Aim: We aimed to investigate differences in cerebro- and cardiovascular comorbidities by psoriasis severity.

Materials and methods: Using Swedish nationwide health-care registers, new adult users of anti-psoriatic drugs (2007-2013) with a recorded diagnosis of psoriasis/psoriatic arthritis or a filled prescription for calcipotriol were included. Psoriasis severity was based on the type of anti-psoriatic treatment (topical/mild, non-biologic systemic/moderate-to-severe, and biologics/ severe). Age standardized prevalence rates of cerebro- and cardiovascular comorbidities and their risk factors were compared between the groups.

Results: We found that severe psoriasis patients $(\mathrm{N}=2147)$ were younger than moderate-to-severe $(\mathrm{N}=11,919)$ or mild $(\mathrm{N}=70,796)$ patients (median 44,52 , and 55 years). Prevalence of hypertension was $29.9 \%, 32.6 \%$, and $36.5 \%$, myocardial infarction was $2.5 \%, 2.3 \%$, and $1.8 \%$, and stroke was $2.4 \%, 2.2 \%$, and $1.1 \%$ in mild, moderate-to-severe, and severe psoriasis patients, respectively. Diabetes prevalence was $7.6 \%$ in mild, $8.0 \%$ in moderate-to-severe, and $10.7 \%$ in severe psoriasis. Conclusion: Myocardial infarction and stroke were less common in patients with severe psoriasis while, despite being younger, they had a higher prevalence of diabetes and hypertension. Keywords: psoriasis, severity, cardiovascular, cerebrovascular, prevalence
\end{abstract}

\section{Introduction}

Prevalence of psoriasis, a common chronic inflammatory disease, is around $0.09 \%-$ $11.4 \%$ in the world ${ }^{1,2}$ and $2 \%-4 \%$ in most developed countries. ${ }^{2-4}$ In recent years, psoriasis has been considered to be associated with diseases, such as cardiovascular diseases (CVDs) and metabolic disorders (MDs)..$^{5-7}$

Hypertension (HTN) has proved more common in psoriatic patients than in the general population. ${ }^{8-11}$ Psoriasis has also been associated with a higher risk of myocardial infarction (MI $)^{12}$ even after adjustment for known risk factors. ${ }^{13}$ Few studies, however, have examined how these comorbidities vary based on the psoriasis severity. Armstrong and Harskamp ${ }^{14}$ reported that the risk of HTN is increased in patients with severe psoriasis compared with a mild condition. Mehta et $\mathrm{al}^{13}$ found that the severity of psoriasis was associated with the major CVD events: MI and stroke. With respect to MDs, studies have indicated that diabetes mellitus (DM) is more prevalent among psoriatic patients, ${ }^{12}$ especially among patients with severe disease. ${ }^{11,15}$ Psoriasis has also been found an independent risk factor of type 2 DM after controlling for age, sex, body mass index, HTN, and hyperlipidemia. ${ }^{11}$

\footnotetext{
Correspondence: Mohammadhossein Hajiebrahimi

Center for Pharmacoepidemiology, Department of Medicine, Karolinska Institutet, SE-I7I 76 Stockholm, Sweden Tel +46085 I77 I0I7

Fax +46085 I779304

Email Mohammadhossein.Hajiebrahimi @ki.se
} 
Despite this knowledge, our study aims to investigate the prevalence of cerebro- and cardiovascular comorbidities in a larger sample of psoriasis patients, as prior studies are limited due to the relatively small sizes. We used a large nationwide population of psoriasis patients, to find the prevalence of comorbidities during the 5-year period preceding treatment initiation (untreated time) for psoriasis or psoriatic arthritis.

\section{Materials and methods}

Using the National Patient Register (NPR) and the Prescribed Drug Register (PDR) covering the Swedish population, we identified patients with either a diagnosis of psoriasis/psoriatic arthritis and/or calcipotriol treatment. The first dispensing of a psoriasis medication was then identified to determine inclusion eligibility. The NPR ${ }^{16}$ has recorded inpatient hospital discharge diagnoses since 1964, with complete national coverage since 1987. The current completeness of the register is $>99 \% .{ }^{16}$ Starting in 2001, diagnoses from outpatient visits at hospital are also registered. Details on all drugs dispensed at pharmacies by personal prescriptions to the entire Swedish population are registered in the PDR since 1st July 2005. ${ }^{17}$ Drugs are classified according to the Anatomical Therapeutic Chemical (ATC) classification system. ${ }^{18}$ Drug treatment during inpatient hospital care and purchases of over-the-counter medications are not recorded. Migration data were retrieved from the Total Population Register, which has collected computerized demographic data since $1968 .{ }^{19}$ All registers were linked using the unique personal identity number assigned to all Swedish residents since 1947.

A flow diagram of patients with psoriasis according to the inclusion and exclusion criteria for this study is shown in Figure S1. Patients with a main diagnosis of psoriasis or psoriatic arthritis between 1968 and 2013 (Table S1) were identified in NPR. The patients who subsequently filled at least 1 dispensing of an anti-psoriatic drug (Table S2) between 1 July 2007 and 31 December 2013, without a prior dispensing of these medications since 1 July 2005, were eligible for inclusion. In order to identify psoriatic patients diagnosed in primary care (not recorded in NPR), we also included patients who filled at least 1 dispensing of calcipotriol with/without corticosteroids (ATC-codes D05AX02, D05AX52) during the same time-interval of 1 July 2007 to 31 December 2013, without such drugs dispensed between 1 July 2005 and 30 June 2007. Only patients aged $>18$ years at the date of the first dispensing were included. All patients from the topical treatment group who were dispensed a nonbiological or a biological treatment before topical treatment index date (the first dispensing date of anti-psoriatic drugs in each treatment group) and all patients in non-biological treatment group who received a biological drug before their index date were excluded. Patients were also excluded if they migrated to/from Sweden during the 5-year period prior to therapy initiation because these patients did not have full 5-year coverage of comorbidity history in the national registers. Since we only included patients without treatment of psoriasis (or psoriatic arthritis) between 1 July 2005 and 30 June 2007, we restricted our study population to those with little or no disease activity during at least 2 years preceding the new anti-psoriatic treatment.

We classified psoriatic patients (including psoriatic arthritis) based on the type of the dispensed anti-psoriatic drugs: 1) topical group (calcipotriol with/without corticosteroids), 2) non-biological systemic group (methotrexate, cyclosporine, acitretin, or phototherapy), and 3) biological group (adalimumab, etanercept, infliximab, efalizumab, ustekinumab, certolizumab, or golimumab). These treatments have been shown to correlate with increasing psoriasis severity, ranging from mild (topical) to moderate (non-biologic systemics) to severe (biologics). ${ }^{20,21}$ We used calcipotriol with/without corticosteroids as the proxy to identify the mild psoriasis group since this drug is used exclusively to treat mild psoriasis. ${ }^{22}$ We chose not to include drugs, such as corticosteroids, coal tar, vitamin D, etc., which are also used for other indications than psoriasis. This selection is conservative as it possibly identifies patients with psoriasis disease, but may lead to a lower sample size. Patients were allowed to be included in more than 1 treatment group if they were treated with different drug types, as long as the treatment groups followed the hierarchical treatment sequence: topical to non-biologic systemic to biologics. Concurrent use was classified to the most potent group; for example, a patient prescribed adalimumab and methotrexate on the same date, was classified into the biological group since adalimumab is used for the treatment of severe psoriasis.

Individuals with CVD comorbidities and risk factors were identified in both NPR and PDR (Table S3). CVDs, such as MI, angina pectoris, atrial fibrillation, stroke, heart failure, and hypertensive diseases were identified from NPR 5 years prior to index date. The diseases were captured from primary or secondary diagnosis in either the in- or outpatient settings. The same procedure was used for MDs, all of which are risk factors for CVDs. Data on HTN and DM were identified both in NPR and by filled prescriptions in PDR. We are limited in identifying HTN, DM, and hyperlipidemia in NPR, since these diseases are often diagnosed and treated 
in primary health centers. Therefore, dispensed drugs from PDR was used as a proxy to identify these comorbidities. The dispensed drugs were identified during a 2-year period prior to index date.

The study was approved by the Research Ethics Committee of Karolinska Institutet (Approval 2009/1250_31/4).

\section{Statistical analysis}

We estimated the prevalence rate of the comorbidities during 5 years before initiation of the treatment among psoriasis patients with mild, moderate-to-severe, and severe psoriasis based on anti-psoriatic treatments. In fact, our study includes only the untreated time preceding the treatment for each treatment type. We identified age and sex as confounders potentially affecting the prevalence rates of comorbidities. In order to attenuate possible differences in age between the treatment groups, we compared the prevalence rates of the comorbidities during 5 years before initiation of anti-psoriasis treatment after standardization by age. The overall Swedish age distribution in 2013 was used as the standard. Since the prevalence of CVDs is different between sexes, subgrouping was used to handle this confounding. As measure of precision 95\% CIs were calculated around the prevalence rates. To compare the results between the 3 different treatment groups, we used overlaps of the $95 \%$ CIs to assess statistical significance. We moreover compared our results with the prevalence of the comorbidities in the general population, which was retrieved from other studies in Sweden or from The National Board of Health and Welfare. Analyses were carried out using SAS ${ }^{\circledR}$ version 9.4, SAS Institute, Cary, NC, USA and STATA version 12 (College Station, TX: StataCorp LP).

\section{Results}

Table 1 presents the baseline characteristics of the study population by treatment group/psoriasis severity. Patients with severe psoriasis, that is, those starting a biologic treatment, were younger (median 44 years, interquartile range [IQR]: 34-55) than the patients with a moderate-to-severe psoriasis (starting a non-biologic systemic treatment) (median 52 years, IQR: 41-62) or with a mild psoriasis (starting a topi-

Table I Baseline characteristics of adult patients with psoriasis by treatment groups

\begin{tabular}{|c|c|c|c|c|c|c|}
\hline \multirow[t]{3}{*}{ Patients characteristics } & \multicolumn{2}{|c|}{$\begin{array}{l}\text { Topical } \\
\text { treatments }^{\mathrm{a}}\end{array}$} & \multicolumn{2}{|c|}{$\begin{array}{l}\text { Non-biological } \\
\text { systemic treatment }^{\mathrm{b}}\end{array}$} & \multicolumn{2}{|l|}{$\begin{array}{l}\text { Biological } \\
\text { treatment }^{c}\end{array}$} \\
\hline & Number & Percent & Number & Percent & Number & Percent \\
\hline & 70796 & & 11919 & & 2147 & \\
\hline \multicolumn{7}{|c|}{ Age (years) at first dispensing at index date } \\
\hline$<30$ & 7005 & 9.9 & 983 & 8.3 & 326 & 15.2 \\
\hline $30-39$ & 9323 & 13.2 & 1678 & 14.1 & 484 & 22.5 \\
\hline $40-49$ & 11347 & 16.0 & 2508 & 21.0 & 543 & 25.3 \\
\hline $50-59$ & 14999 & 21.2 & 3008 & 25.2 & 478 & 22.3 \\
\hline $60-69$ & 16109 & 22.8 & 2505 & 21.0 & 266 & 12.4 \\
\hline $70-79$ & 8272 & 11.7 & 1001 & 8.4 & 47 & 2.2 \\
\hline$\geq 80$ & 3741 & 5.3 & 236 & 2.0 & 3 & 0.1 \\
\hline Median (IQR) & $55.0(4 I-66)$ & & $52.0(4 I-62)$ & & $44.0(34-55)$ & \\
\hline \multicolumn{7}{|l|}{ Year of first dispensing } \\
\hline $2007^{d}$ & 5525 & 7.8 & 776 & 6.5 & 49 & 2.3 \\
\hline 2008 & 10936 & 15.5 & 1682 & 14.1 & 220 & 10.3 \\
\hline 2009 & 11470 & 16.2 & 1715 & 14.4 & 231 & 10.7 \\
\hline 2010 & 11950 & 16.9 & 1834 & 15.4 & 289 & 13.5 \\
\hline 2011 & 11415 & 16.1 & 2002 & 16.8 & 382 & 17.7 \\
\hline 2012 & 10540 & 14.9 & 1972 & 16.6 & 442 & 20.6 \\
\hline 2013 & 8960 & 12.7 & 1938 & 16.3 & 534 & 24.9 \\
\hline \multicolumn{7}{|c|}{ Number of outpatient visits within I year before index date } \\
\hline 0 & 34835 & 49.2 & 3941 & 33.1 & 503 & 23.4 \\
\hline I & 12844 & 18.1 & 2179 & 18.3 & 298 & 13.9 \\
\hline 2 & 7537 & 10.7 & 1488 & 12.5 & 269 & 12.5 \\
\hline $3+$ & 15580 & 22.0 & 4311 & 36.2 & 1077 & 50.2 \\
\hline Mean $( \pm S D)$ & I.7 $( \pm 4.1)$ & & $2.9( \pm 5.1)$ & & $4.1( \pm 5.4)$ & \\
\hline Median (IQR) & I (0-2) & & I (0-4) & & $3(I-6)$ & \\
\hline
\end{tabular}

Notes: ${ }^{a}$ Topical treatment with calcipotriol or calcipotriol combinations. ${ }^{b}$ Non-biological systemic treatment with methotrexate, cyclosporine, acitretin and phototherapy. 'Biological treatment with adalimumab, etanercept, infliximab, efalizumab, ustekinumab, certolizumab, golimumab. ${ }^{\mathrm{d}}$ Patients identified in 2007 were only captured in the study population if they had an index date on or after Ist July 2007.

Abbreviation: IQR, interquartile range. 
cal treatment) (median 55 years, IQR: 41-66). We further found that treatment with biological drugs increased - in absolute number of individuals - during the study period, while treatment with non-biological systemic drugs did not change substantially, and topical treatment decreased.

The standardized rates of comorbidities at baseline in the 3 different treatment categories are presented in Table 2, with 95\% CI. Major cardio- and cerebrovascular diseases were less common in patients starting biologic treatment/severe disease (point estimate [95\% CI]); MI: 1.82\% (1.29-2.47), Stroke: $1.07 \%$ (0.68-1.60) compared with moderate-tosevere patients starting non-biological systemic treatment; MI: 2.30\% (2.03-2.58), Stroke: 2.16\% (1.90-2.43) and mild patients starting topical treatment; MI: 2.50\% (2.39-2.62), Stroke: $2.42 \%$ (2.31-2.53). With regard to MDs and HTN, the standardized rates were similar between the groups but higher in the population of patients starting biologic treatments, despite their younger age, for example, HTN: starters of biologic treatment: $36.47 \%(34.42-38.55)$; non-biological systemic treatment: $32.62 \%$ (31.77-33.47); and topical treatment: $29.88 \%$ (29.54-30.21); and diabetes: starters of biologic treatment: $10.67 \%(9.39-12.05)$; non-biological systemic treatment: $8.00 \%(7.52-8.51)$; and topical treatment: $7.60 \%$ (7.41-7.80).

Estimating the prevalence rates by sex showed that the prevalence of MI and stroke was higher among men. However, the decreasing pattern of the prevalence of these diseases is almost the same by severity. Moreover, although the increasing pattern of the prevalence of the risk factors of CVDs: HTN and DM, by sex is similar to the overall results, the prevalence of these comorbidities is higher among females with moderate-to-severe and severe psoriasis than in men (Table S4).

\section{Discussion}

In this large population-based cross-sectional study, using Swedish national health registers, we identified $>80,000$ patients with psoriasis (or psoriatic arthritis) receiving antipsoriatic treatment between 1 July 2007 and 31 December 2013. Close to 75,000 patients started a topical treatment with calcipotriol - suffering from mild psoriasis; around 12,000 patients started treatment with non-biological systemic drugs - assumed to suffer from moderate-to-severe psoriasis; and $\sim 2200$ started a biologic regimen - the patient group with presumably the most severe psoriasis. Including only naïve users and applying hierarchical classification led to a higher proportion of mild cases and a lower proportion of severe cases than observed in other studies. The 3 groups were investigated and compared with regard to cerebro- and cardiovascular comorbidities and selected early risk factors during a 5-year period before starting treatment (a 2-year period for conditions identified by dispensed prescribed drugs). We found that the standardized prevalence of the major cardio- and cerebrovascular outcomes (i.e., MI and

Table 2 Age-standardized prevalence of baseline comorbidities in adult patients with psoriasis by severity of the disease

\begin{tabular}{|c|c|c|c|c|c|c|c|c|c|}
\hline \multirow[t]{3}{*}{ Comorbidities } & \multicolumn{3}{|c|}{ Mild psoriasis $^{a}$} & \multicolumn{3}{|c|}{$\begin{array}{l}\text { Moderate-to-severe } \\
\text { psoriasis }^{b}\end{array}$} & \multicolumn{3}{|c|}{ Severe psoriasis $^{c}$} \\
\hline & No. & $\%$ & $95 \% \mathrm{Cl}$ & No. & $\%$ & $95 \% \mathrm{Cl}$ & No. & $\%$ & $95 \% \mathrm{Cl}$ \\
\hline & \multicolumn{3}{|l|}{70796} & \multicolumn{3}{|l|}{11919} & \multicolumn{3}{|l|}{2147} \\
\hline \multicolumn{10}{|l|}{ Cardiovascular diseases } \\
\hline Myocardial infarction & 2070 & 2.50 & $2.39-2.62$ & $27 \mid$ & 2.30 & $2.03-2.58$ & 27 & 1.82 & $1.29-2.47$ \\
\hline Angina pectoris & 2112 & 2.55 & $2.43-2.67$ & 307 & 2.63 & $2.36-2.94$ & 43 & 2.24 & $1.65-2.95$ \\
\hline Peripheral arterial disease $^{d}$ & 1449 & 1.75 & $1.66-1.85$ & 213 & 1.77 & $1.54-2.02$ & 21 & 3.26 & $2.55-4.10$ \\
\hline Atrial fibrillation & 2454 & 3.13 & $3.00-3.26$ & 330 & 3.16 & $2.85-3.49$ & 44 & 2.19 & $1.61-2.90$ \\
\hline Heart failure and hypertensive diseases & 2913 & 3.74 & $3.60-3.87$ & 395 & 3.74 & $3.40-4.09$ & 59 & 5.08 & 4.19-6.09 \\
\hline Essential hypertension ${ }^{d}$ & 25075 & 29.88 & $29.54-30.21$ & 4183 & 32.62 & $31.77-33.47$ & 665 & 36.47 & $34.42-38.55$ \\
\hline \multicolumn{10}{|l|}{ Cerebrovascular diseases } \\
\hline Stroke & 1918 & 2.42 & $2.31-2.53$ & 238 & 2.16 & $1.90-2.43$ & 21 & 1.07 & $0.68-1.60$ \\
\hline Transient ischemic attack & 612 & 0.76 & $0.70-0.83$ & 81 & 0.75 & $0.60-0.92$ & 9 & 0.51 & $0.26-0.91$ \\
\hline \multicolumn{10}{|l|}{ Metabolic diseases } \\
\hline Diabetes $^{d}$ & 6288 & 7.60 & $7.4 I-7.80$ & 1018 & 8.00 & $7.52-8.51$ & 162 & 10.67 & $9.39-12.05$ \\
\hline Treatment with statins & 11804 & 13.50 & $13.25-13.76$ & 1814 & $13.6 \mid$ & $13.00-14.23$ & 241 & 16.44 & $14.90-18.08$ \\
\hline Obesity & 1419 & 1.97 & $1.87-2.07$ & 294 & 2.40 & $2.13-2.69$ & 56 & 1.96 & $1.4 \mid-2.64$ \\
\hline \multicolumn{10}{|l|}{ Other disease } \\
\hline Chronic obstructive pulmonary disease & 2715 & 3.58 & $3.45-3.72$ & 520 & 4.60 & $4.24-5.00$ & 107 & 4.70 & $3.85-5.69$ \\
\hline
\end{tabular}

Notes: ${ }^{a}$ Topical treatment with calcipotriol or calcipotriol combinations. ${ }^{b}$ Non-biological systemic treatment with methotrexate, cyclosporine, acitretin and phototherapy. 'Biological treatment with adalimumab, etanercept, infliximab, efalizumab, ustekinumab, certolizumab, golimumab. ${ }^{\mathrm{d} D a t a}$ obtained from both Swedish National Patient Register and Prescribed Drug Register (Table S3). 
stroke) were less frequent in patients with severe psoriasis, as would be expected since this population is younger than those with a mild or moderate-to-severe condition. On the contrary, conditions representing early risk factors for CVD events, were as common or more common in patients with severe psoriasis, despite their younger age. Therefore, at the start of biologic treatment, the more severely ill psoriasis patients appear to already suffer from early warning signs for a serious condition that has yet to manifest.

Consistent with previously published studies, our study shows that the prevalence of CVDs may be influenced by severity of psoriasis. Al-Mutairi et $\mathrm{al}^{23}$ conducted a casecontrol study on 1835 patients with psoriasis vulgaris and their matched non-psoriatic controls. They found that the prevalence of HTN was $32.0 \%, 40.3 \%$, and $11.6 \%$ among those with mild-to-moderate psoriasis, severe psoriasis, and controls, respectively. Through a meta-analysis of observational studies, Armstrong et $\mathrm{al}^{14}$ have concluded that patients with severe psoriasis have a higher risk of HTN compared with mild psoriatic patients. In the present study, the agestandardized prevalence of HTN was found to be $29.9 \%$, $32.6 \%$, and $36.5 \%$ among patients with mild, moderate-tosevere, and severe psoriasis, respectively.

Compared with the prevalence of HTN in the general population of Sweden $(20 \%),{ }^{24}$ the results from our study show an approximately 2-fold higher prevalence of HTN in severe psoriasis patients. In this study, the prevalence of other CVDs, for example, MI or stroke was found to be $2.5 \%, 2.3 \%$, and $1.8 \%$ for MI, and $2.4 \%, 2.2 \%$, and $1.1 \%$ for stroke in patients with mild, moderate-to-severe, and severe psoriasis, respectively. This is higher than the prevalence of these diseases in the general population of Sweden (MI: $0.4 \%$, stroke: $0.3 \%) .^{25,26}$

Respective prevalence rates of DM in mild, moderate-tosevere, and severe psoriasis in our study were $7.6 \%, 8.0 \%$, and $10.7 \%$. The observed increasing prevalence of DM is supported by previous studies showing increased prevalence of DM with increasing severity of psoriasis. Neimann et $\mathrm{al}^{15}$ have shown, through a cross-sectional study in the UK, that the prevalence of $\mathrm{DM}$ is $4.4 \%$ and $7.1 \%$ among patients with mild and severe psoriasis, respectively, compared with non-psoriatic controls with a prevalence of 3.3\%. Al-Mutairi et $\mathrm{al}^{23}$ have reported the prevalence of DM (type 2) among psoriatic patients as: $37.4 \%$ in mild-to-moderate psoriasis, $41.0 \%$ in severe psoriasis, and $16.0 \%$ in control patients without psoriasis. Despite the similarity of the direction between the previous ${ }^{15,23}$ and this study, the variability observed might originate from differences in the definition of the psoriasis severity. In Neimann et $\mathrm{a}^{15}$ all patients who received psoralen, phototherapy, methotrexate, azathioprine, cyclosporine, etretinate, acitretin, hydroxyurea, and mycophenolate were considered as severe psoriasis patients and biological treatments were not used in that study. Moreover, the registry used only records visits to general practitioners, while our study covers specialist clinics, hospital admissions, as well as general practitioner visits estimated from prescription claims. In Al-Mutairi et $\mathrm{al}^{23}$ the Psoriasis Area Severity Index (PASI) was used to measure the severity of the psoriasis and the outcome of interest was type 2 diabetes. We also compared comorbidity rates with the general population of Sweden, and found that the prevalence of DM in our study is higher than that of the general population: a total of $7.6 \%$, $8.0 \%$, and $10.7 \%$ in the mild, moderate-to-severe, and severe groups, respectively, versus $6.2 \%^{27}$ to $6.8 \%{ }^{28}$ in the Swedish general population.

One explanation of higher prevalence of risk factors and lower prevalence of the major events of CVDs in the severe psoriasis group (younger patients) could be the nature of the psoriasis. Psoriasis onset at a younger age ( $\leq 40$ years old) or early-onset disease $\mathrm{e}^{29,30}$ has been shown to have a higher inflammatory reaction, extensive cutaneous involvement, and more severe clinical course ${ }^{31-33}$ compared with older age/ late onset of psoriasis. Therefore, it is reasonable to expect a higher rate of the CVD risk factors, such as HTN and DM among younger psoriasis patients due to a possible shared pathologic mechanism between CVDs and psoriasis. With regard to major cardiovascular events, such as MI or stroke, it may be that these events need a longer time to manifest. Therefore, it could be expected to find a higher rate of early risk factors of CVDs while the prevalence of the major events of CVDs is yet to manifest in our data due to right censoring.

The strengths of our study include the population-based design, the national coverage of the registers being close to $100 \%$, the long study period, and the large sample size compared with prior works. By use of both NPR and PDR, we were able to include as many patients as possible with psoriasis (including psoriatic arthritis) in the study, that is, patients treated in both primary care and by specialists at hospitals. This study is the first Swedish nationwide investigation on prevalence of CVD and DM among psoriatic patients. Our findings support existing information on the prevalence of these comorbidities among psoriasis patients. Our study also used a 5-year period before starting the anti-psoriatic treatments to quantify the prevalence of comorbidities. Our 
results could be generalized to similar populations due to its population-based design and large sample size. A limitation of our study is using treatment types to measure psoriasis severity. A more direct severity measure, such as PASI is more ideal, however, these data are not captured in Swedish national health registers. However, using anti-psoriatic treatment as a proxy for severity of the disease has been estimated to have a sensitivity and positive predictive value of more than $90 \%$ and $80 \%$, respectively. ${ }^{20,21} \mathrm{~A}$ second potential limitation is the overlap between mild and moderate-to-severe treatment groups, when we use the treatment as a proxy. For example, some types of psoriasis, such as guttate psoriasis are frequently treated with cyclosporine even when these cases are considered mild. However, this did not have a major impact on our results as the prevalence of guttate psoriasis is low (around $2 \%)^{34}$ and typically occurs in children who were excluded from this study. A third potential limitation is due to the lack of coverage of PDR for drugs prescribed at a hospital. Some drugs, such as infliximab, are prescribed in hospital and do not appear in PDR. There may be an underestimation for drugs prescribed at hospitals when we rely on the PDR to create the treatment groups. Fourth, we also lacked information on physical activity, tobacco use, diet, and central obesity as these are not available in the national Swedish registers. As the last limitation, we had no information about the indication for the drugs prescribed: both non-biological systemic drugs and biologics can be used for other indications beyond psoriasis and psoriatic arthritis. However, all patients except those identifying just in PDR (calcipotriol users in primary health care centers) had a diagnosis of psoriasis or psoriatic arthritis recorded in the NPR.

\section{Conclusion}

Despite the younger age of patients with severe psoriasis, that is, those starting a biologic treatment, the prevalence of early risk factors for cardio- and cerebrovascular disease was higher than in the older patients with a mild or moderate-tosevere psoriasis, or those starting a topical or non-biologic systemic treatment. A health policy implication from our results is that all patients suffering from severe psoriasis should be carefully monitored with regard to signs and symptoms of metabolic conditions as early signs of cerebro- and cardiovascular disease.

\section{Acknowledgments}

This project was funded via the public-private real world evidence collaboration between Karolinska Institutet and Janssen Pharmaceuticals (contract: 5-63/2015).

\section{Author contributions}

$\mathrm{MH}$ had full access to all data in the study and takes responsibility for the integrity of the data and accuracy of the data analysis. AS, ML, and IAB performed the study concept and design. MH performed the analysis and AS, ML, IAB, DH and $\mathrm{MH}$ performed the interpretation of data. $\mathrm{MH}$ drafted the manuscript. All co-authors performed critical revision of the manuscript for important intellectual content. All authors contributed toward data analysis, drafting and revising the paper and agree to be accountable for all aspects of the work.

\section{Disclosure}

The authors report no conflicts of interest in this work.

\section{References}

1. Danielsen K, Olsen AO, Wilsgaard T, Furberg AS. Is the prevalence of psoriasis increasing? A 30-year follow-up of a population-based cohort. Br J Dermatol. 2013;168(6):1303-1310.

2. WHO. Global report on psoriasis; 2016. World Health Organization. Available from: http://www.who.int/iris/handle/10665/204417. Accessed May 1, 2018.

3. Christophers E. Psoriasis- epidemiology and clinical spectrum. Clin Exp Dermatol. 2001;26(4):314-320.

4. Parisi R, Symmons DP, Griffiths CE, Ashcroft DM; Identification and Management of Psoriasis and Associated ComorbidiTy (IMPACT) project team. Global epidemiology of psoriasis: a systematic review of incidence and prevalence. J Invest Dermatol. 2013;133(2):377-385.

5. Duffin KC. Identifying and managing complications and comorbidities in patients with psoriasis. Paper presented at: Seminars in Cutaneous Medicine and Surgery; 2015.

6. Shah K, Mellars L, Changolkar A, Feldman SR. Real-world burden of comorbidities in US patients with psoriasis. $J$ Am Acad Dermatol. 2017;77(2):287-292.e4.

7. Thomas J, Kumar NA, Manoharan D, Cynthia S, Prabu SS, Ahmed NA. A study of comorbid conditions in psoriasis. J Pak Assoc Dermatol. 2016;19(4):200-202.

8. Armesto S, Coto-Segura P, Osuna C, Camblor P, Santos-Juanes J. Psoriasis and hypertension: a case-control study. J Eur Acad Dermatol Venereol. 2012;26(6):785-788.

9. Cohen AD, Weitzman D, Dreiher J. Psoriasis and hypertension: a casecontrol study. Acta Derm Venereol. 2010;90(1):23-26.

10. Gottlieb AB, Dann F. Comorbidities in patients with psoriasis. Am J Med. 2009;122(12):1150.e1-e9.

11. Ni C, Chiu MW. Psoriasis and comorbidities: links and risks. Clin Cosmet Investig Dermatol. 2014;7:119-132.

12. Yeung H, Takeshita J, Mehta NN, et al. Psoriasis severity and the prevalence of major medical comorbidity: a population-based study. JAMA Dermatol. 2013;149(10):1173-1179.

13. Mehta NN, Yu Y, Pinnelas R, et al. Attributable risk estimate of severe psoriasis on major cardiovascular events. Am J Med. 2011;124(8):775. e1-e6.

14. Armstrong AW, Harskamp CT, Armstrong EJ. The association between psoriasis and hypertension: a systematic review and meta-analysis of observational studies. J Hypertens. 2013;31(3):433-443.

15. Neimann AL, Shin DB, Wang X, Margolis DJ, Troxel AB, Gelfand JM. Prevalence of cardiovascular risk factors in patients with psoriasis. $\mathrm{JAm}$ Acad Dermatol. 2006;55(5):829-835.

16. Ludvigsson JF, Andersson E, Ekbom A, et al. External review and validation of the Swedish national inpatient register. BMC Public Health. 2011;11(1):450. 
17. Wettermark B, Hammar N, Fored CM, et al. The new Swedish prescribed drug register-opportunities for pharmacoepidemiological research and experience from the first six months. Pharmacoepidemiol Drug Saf. 2007;16(7):726-735.

18. WHO. WHO collaborating center for Drug Statistics Methodology; 2016. Available from: https://www.whocc.no/atc_ddd_index. Accessed June 26, 2016.

19. Ludvigsson JF, Almqvist C, Bonamy AK, et al. Registers of the Swedish total population and their use in medical research. Eur J Epidemiol. 2016;31(2):125-136.

20. Egeberg A, Gyldenlove M, Zachariae C, Skov L. Validation of psoriasis severity classification based on use of topical or systemic treatment. J Eur Acad Dermatol Venereol. 2018;32(1):e4-e5.

21. Loft N, Skov L, Bryld LE, Gislason G, Egeberg A. Treatment history of patients receiving biologic therapy for psoriasis - a Danish nationwide study. J Eur Acad Dermatol Venereol. 2017;31(8):e362-e363.

22. Norlin JM, Steen Carlsson K, Persson U, Schmitt-Egenolf M. Resource use in patients with psoriasis after the introduction of biologics in Sweden. Acta Derm Venereol. 2015;95(2):156-161.

23. Al-Mutairi N, Al-Farag S, Al-Mutairi A, Al-Shiltawy M. Comorbidities associated with psoriasis: an experience from the Middle East. J Dermatol. 2010;37(2):146-155.

24. Lindblad U, Ek J, Eckner J, Larsson CA, Shan G, Råstam L. Prevalence, awareness, treatment, and control of hypertension: rule of thirds in the Skaraborg project. Scand J Prim Health Care. 2012;30(2):88-94.

25. Hammar N, Alfredsson L, Rosen M, Spetz CL, Kahan T, Ysberg AS. A national record linkage to study acute myocardial infarction incidence and case fatality in Sweden. Int J Epidemiol. 2001;30(Suppl 1):S30-S34.
26. Malki N, Koupil I, Eloranta S, et al. Temporal trends in incidence of myocardial infarction and ischemic stroke by socioeconomic position in Sweden 1987-2010. PLoS One. 2014;9(8):e105279.

27. Carlsson AC, Wändell P, Ösby U, Zarrinkoub R, Wettermark B, Ljunggren G. High prevalence of diagnosis of diabetes, depression, anxiety, hypertension, asthma and COPD in the total population of Stockholm, Sweden-a challenge for public health. BMC Public Health. 2013;13(1):670.

28. Andersson T, Ahlbom A, Carlsson S. Diabetes prevalence in Sweden at present and projections for year 2050. PLoS One. 2015;10(11):e0143084.

29. Rahman P, Schentag CT, Gladman DD. Immunogenetic profile of patients with psoriatic arthritis varies according to the age at onset of psoriasis. Arthritis Rheum. 1999;42(4):818-823.

30. Smith AE, Kassab JY, Rowland Payne CM, Beer WE. Bimodality in age of onset of psoriasis, in both patients and their relatives. Dermatology. 1993;186(3):181-186.

31. Ferrándiz C, Pujol RM, García-Patos V, Bordas X, Smandía JA. Psoriasis of early and late onset: a clinical and epidemiologic study from Spain. J Am Acad Dermatol. 2002;46(6):867-873.

32. Kwon HH, Kwon IH, Youn JI. Clinical study of psoriasis occurring over the age of 60 years: is elderly-onset psoriasis a distinct subtype? Int $J$ Dermatol. 2012;51(1):53-58.

33. Melski JW, Stern RS. The separation of susceptibility to psoriasis from age at onset. J Invest Dermatol. 1981;77(6):474- 477.

34. Langley RG, Krueger GG, Griffiths CE. Psoriasis: epidemiology, clinical features, and quality of life. Ann Rheum Dis. 2005;64(Suppl 2): ii18-ii23. 


\section{Supplementary materials}

Table SI ICD codes for psoriasis and psoriatic arthritis ${ }^{1-4}$

\begin{tabular}{lll}
\hline ICD-8 & ICD-9 & ICD-10 \\
\hline 6960 (Psoriatic arthritis opathica) & 696A (Psoriatic joint disease) & L40 (Psoriasis) \\
6961 (Psoriasis pustulosa and all sites NUD [vulgaris]) & 696B (Other psoriasis) & M070 (Distal interphalangeal psoriatic arthropathy) \\
69698 (All cause psoriasiformes) & 696F (Other and unspecified scaling) & M07I (Arthritis mutilans) \\
& 696W (Other psoriasis-like state) & M072 (Psoriatic spondylitis) \\
& 7I3D (Arthropathy and skin diseases) & M073 (Other psoriatic arthropathies) \\
\hline
\end{tabular}

Abbreviations: ICD, International Classification of Diseases.

Table S2 List of ATC codes used for identifying the treatment groups

\begin{tabular}{ll}
\hline Treatment & ATC code (Old code) \\
\hline Topical treatment & D05AX02 \\
Calcipotriol & D05AX52 \\
Calcipotriol, combinations & \\
Non-biological systemic treatment & Procedure code \\
Phototherapy & DQ0I0 (Surgical Procedure codes) \\
Phototherapy, PUVA, oral & DQ0II (Surgical Procedure codes) \\
Phototherapy, PUVA, bath & LOIBA0I \\
Methotrexate & L04AD0I (L04AA0I) \\
Cyclosporine & D05BB02 \\
Acitretin & \\
Biologic systemic treatment & L04AB04 (L04AAI7) \\
Adalimumab & L04AB02 (L04AAI2) \\
Infliximab & LOAAB0I (L04AAII) \\
Etanercept & L04AC05 \\
Ustekinumab & L04AA2I \\
Efalizumab & L04AB05 \\
Certolizumab & LO4AB06 \\
Golimumab & \\
\hline
\end{tabular}

Abbreviations: ATC, Anatomical Therapeutic Chemical Classification System; PUVA, Psoralen and ultraviolet A.

Table S3 List of the codes that were used as comorbidities in the study

\begin{tabular}{|c|c|c|c|}
\hline Diagnosis & ICD-I0 & Surgical Procedure codes & ATC-codes \\
\hline \multicolumn{4}{|l|}{ Cardiovascular diseases } \\
\hline Myocardial infarction & $121,122,123,1241,1252$ & N/A & $\mathrm{N} / \mathrm{A}$ \\
\hline Angina pectoris & 120 & & \\
\hline Peripheral arterial disease & 170, I7I, 1739, 174, K55 & $\begin{array}{l}\text { PAE, PAF, PAH, PAP, PAQ, PBE, PBF, PBH, } \\
\text { PBP, PBQ, PCE, PCF, PCH, PCP, PCQ, } \\
\text { PDE, PDF, PDH, PDP, PDQ, PEE, PEF, } \\
\text { PEH, PEP, PEQ, PFE, PFF, PFH, PFP, PFQ }\end{array}$ & $\mathrm{B} 01 \mathrm{AC} 30$ \\
\hline Atrial fibrillation & 148 & N/A & N/A \\
\hline $\begin{array}{l}\text { Heart failure and hypertensive } \\
\text { diseases }\end{array}$ & $\begin{array}{l}150,1099,111-113,115,134,135 \\
1420,1425-1429,143-147\end{array}$ & N/A & N/A \\
\hline Essential hypertension & 110 & N/A & $\begin{array}{l}\mathrm{C} 02, \mathrm{C} 07, \mathrm{C} 08, \mathrm{C} 09, \\
\mathrm{C} 03 \mathrm{~A}, \mathrm{C} 03 \mathrm{~B}\end{array}$ \\
\hline \multicolumn{4}{|l|}{ Cerebrovascular diseases } \\
\hline Stroke & G45, G46, 163-166, 1693, 1694 & N/A & $N / A$ \\
\hline Transient ischemic attack & G45 & & \\
\hline \multicolumn{4}{|l|}{ Metabolic diseases } \\
\hline Diabetes & EIO, EII & $\mathrm{N} / \mathrm{A}$ & AIOA, AIOB \\
\hline Treatment with statins & & & $\mathrm{ClO}$ \\
\hline Obesity & E65-E66 & & \\
\hline \multicolumn{4}{|l|}{ Other disease } \\
\hline $\begin{array}{l}\text { Chronic obstructive pulmonary } \\
\text { disease }\end{array}$ & $\begin{array}{l}\mathrm{J} 40-\mathrm{J} 47, \mathrm{~J} 60-\mathrm{J} 67, \mathrm{I} 278, \mathrm{I279}, \\
\mathrm{J} 684, \mathrm{~J} 70 \mathrm{I}, \mathrm{J} 703\end{array}$ & $\mathrm{~N} / \mathrm{A}$ & $\mathrm{N} / \mathrm{A}$ \\
\hline
\end{tabular}

Abbreviations: ATC, Anatomical Therapeutic Chemical Classification System; N/A, not applicable. 
Table S4 Age-standardized prevalence of baseline comorbidities in adult patients with psoriasis by severity of the disease and sex

\begin{tabular}{|c|c|c|c|c|c|c|c|c|c|}
\hline \multirow[t]{2}{*}{ Comorbidities by sex } & \multicolumn{3}{|c|}{ Mild psoriasis $^{a}$} & \multicolumn{3}{|c|}{ Moderate-to-severe psoriasis ${ }^{b}$} & \multicolumn{3}{|c|}{ Severe psoriasis $^{c}$} \\
\hline & No. & $\%$ & $95 \% \mathrm{CI}$ & No. & $\%$ & $95 \% \mathrm{Cl}$ & No. & $\%$ & $95 \% \mathrm{Cl}$ \\
\hline Male & 35850 & & & 5605 & & & 988 & & \\
\hline Female & 34946 & & & 6314 & & & 1159 & & \\
\hline \multicolumn{10}{|l|}{ Cardiovascular diseases } \\
\hline \multicolumn{10}{|l|}{ Myocardial infarction } \\
\hline Male & 1357 & 3.40 & $3.21-3.59$ & 185 & 3.55 & $3.08-4.07$ & 19 & 2.73 & $1.80-3.95$ \\
\hline Female & 713 & 1.68 & $1.54-1.82$ & 86 & 1.35 & $1.08-1.66$ & 8 & 1.21 & $0.66-2.02$ \\
\hline \multicolumn{10}{|l|}{ Angina pectoris } \\
\hline Male & 1278 & 3.24 & $3.06-3.43$ & 166 & 3.19 & $2.75-3.69$ & 28 & 3.03 & $2.06-4.30$ \\
\hline Female & 834 & 1.94 & $1.80-2.09$ & $|4|$ & 2.20 & $1.85-2.59$ & 15 & 1.64 & $0.99-2.55$ \\
\hline \multicolumn{10}{|l|}{ Peripheral arterial disease $^{d}$} \\
\hline Male & 833 & 2.11 & $1.97-2.27$ & 134 & 2.62 & $2.22-3.08$ & 12 & 8.10 & $6.47-9.97$ \\
\hline Female & 616 & $\mathrm{I} .44$ & $1.32-1.57$ & 79 & 1.17 & $0.92-1.47$ & 9 & 0.69 & $0.30-1.36$ \\
\hline \multicolumn{10}{|l|}{ Atrial fibrillation } \\
\hline Male & $152 \mid$ & 4.04 & $3.83-4.25$ & 193 & 3.87 & $3.82-4.41$ & 32 & 4.05 & $2.91-5.47$ \\
\hline Female & 933 & 2.28 & $2.13-2.45$ & 137 & 2.55 & $2.18-2.94$ & 12 & 0.87 & $0.4 I-1.58$ \\
\hline \multicolumn{10}{|c|}{ Heart failure and hypertensive diseases } \\
\hline Male & 1664 & 4.45 & $4.24-4.67$ & 215 & 4.17 & $3.67-4.73$ & 35 & 4.05 & $2.91-5.47$ \\
\hline Female & 1249 & 3.10 & $2.92-3.28$ & 180 & 3.33 & $2.90-3.80$ & 24 & 5.26 & $4.05-6.71$ \\
\hline \multicolumn{10}{|l|}{ Essential hypertension ${ }^{d}$} \\
\hline Male & 12549 & 30.27 & $29.79-30.74$ & 1839 & 31.94 & $30.72-33.17$ & 302 & 33.50 & $30.56-36.54$ \\
\hline Female & 12526 & 29.56 & $29.08-30.04$ & 2344 & 33.39 & $32.22-34.56$ & 363 & 37.62 & $34.82-40.48$ \\
\hline \multicolumn{10}{|c|}{ Cerebrovascular diseases } \\
\hline \multicolumn{10}{|c|}{ Stroke } \\
\hline Male & 1116 & 2.96 & $2.78-3.14$ & 123 & 2.46 & $2.07-2.90$ & 8 & 0.80 & $0.35-1.59$ \\
\hline Female & 802 & 1.95 & $1.8 \mathrm{I}-2.10$ & 115 & 1.92 & $1.59-2.29$ & 13 & 1.29 & $0.72-2.13$ \\
\hline \multicolumn{10}{|l|}{ Transient ischemic attack } \\
\hline Male & 347 & 0.91 & $0.82-1.02$ & 42 & 0.89 & $0.66-1.17$ & 2 & 0.10 & $0.00-0.06$ \\
\hline Female & 265 & 0.64 & $0.55-0.72$ & 39 & 0.63 & $0.45-0.86$ & 7 & 0.78 & $0.36-1.47$ \\
\hline \multicolumn{10}{|l|}{ Metabolic diseases } \\
\hline \multicolumn{10}{|l|}{ Diabetes $^{d}$} \\
\hline Male & 3468 & 8.35 & $8.06-8.64$ & 479 & 8.00 & $7.30-8.73$ & 76 & 9.92 & $8.13-11.95$ \\
\hline Female & 2820 & 6.90 & $6.64-7.18$ & 539 & 8.16 & $7.49-8.86$ & 86 & 10.70 & $8.98-12.62$ \\
\hline \multicolumn{10}{|l|}{ Treatment with statins } \\
\hline Male & 6465 & 15.08 & $|4.7|-\mid 5.45$ & 896 & 15.25 & $14.32-15.45$ & 124 & 20.44 & $17.97-23.10$ \\
\hline Female & 5339 & 16.84 & $16.45-17.24$ & 918 & 13.60 & $12.77-14.48$ & 117 & 16.48 & $14.39-18.74$ \\
\hline \multicolumn{10}{|l|}{ Obesity } \\
\hline Male & 505 & 1.27 & $1.16-1.39$ & 96 & 1.53 & $1.23-1.89$ & 15 & 1.11 & $0.56-1.98$ \\
\hline Female & 914 & 2.76 & $2.59-2.93$ & 198 & 3.33 & $2.90-3.80$ & 41 & 2.76 & $1.90-3.88$ \\
\hline \multicolumn{10}{|c|}{ Other disease } \\
\hline \multicolumn{10}{|c|}{ Chronic obstructive pulmonary disease } \\
\hline Male & 1126 & 3.06 & $2.91-3.27$ & 209 & 4.23 & $3.72-4.79$ & 38 & 4.15 & $2.99-5.59$ \\
\hline Female & 1589 & 4.12 & $3.92-4.34$ & 311 & 4.88 & $4.36-5.43$ & 69 & 5.18 & $3.97-6.61$ \\
\hline
\end{tabular}

Notes: ${ }^{a}$ Topical treatment with calcipotriol or calcipotriol combinations. ${ }^{b}$ Non-biological systemic treatment with methotrexate, cyclosporine, acitretin and phototherapy. 'Biological treatment with adalimumab, etanercept, infliximab, efalizumab, ustekinumab, certolizumab, golimumab. 'Data obtained from both Swedish National Patient Register and Prescribed Drug Register (Table S3). 


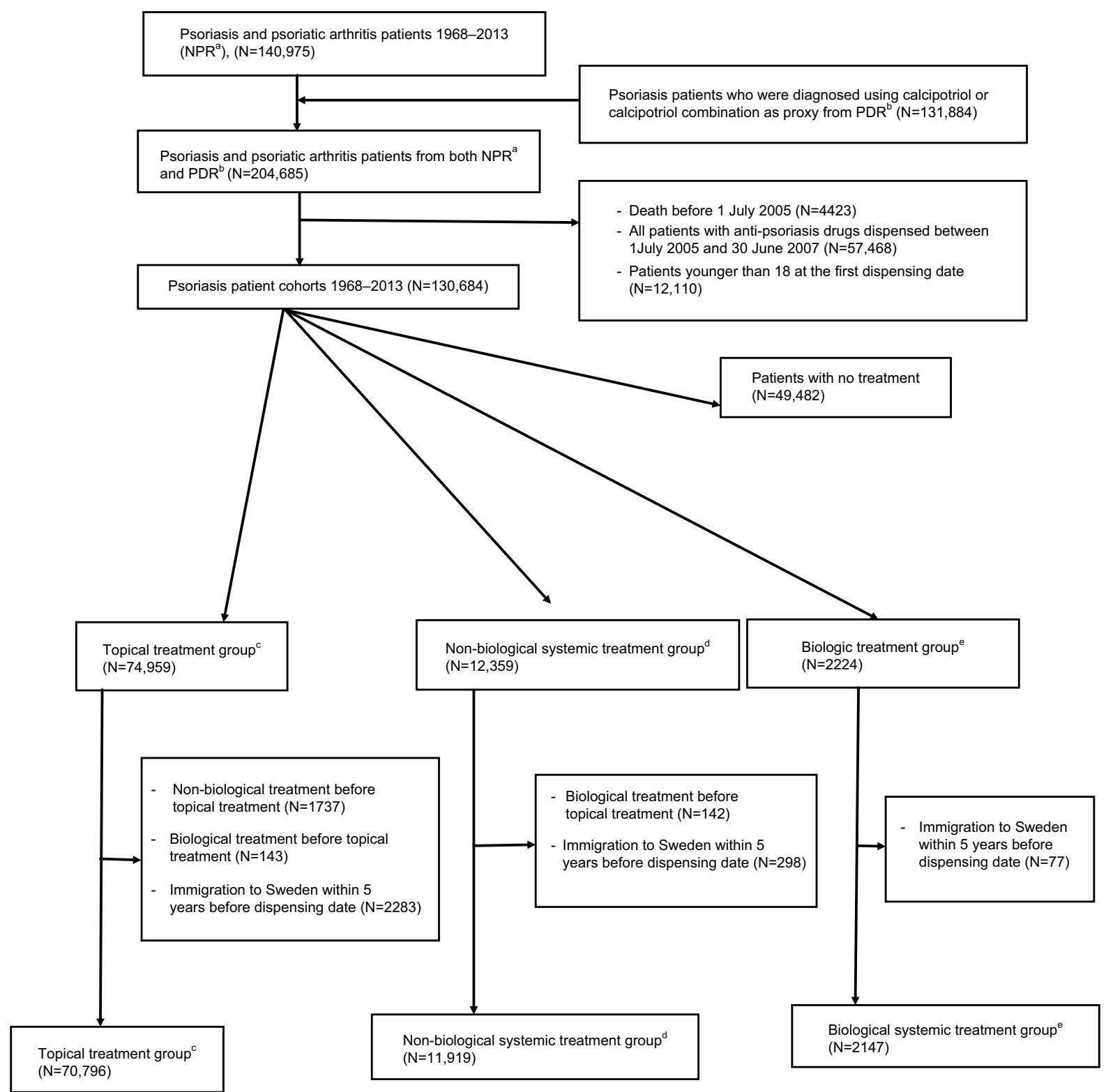

Figure SI The patient flow diagram of creating treatment group datasets among the cohort of psoriasis patients.

Notes: ${ }^{\mathrm{a} N a t i o n a l ~ P a t i e n t ~ R e g i s t e r . ~}{ }^{\mathrm{b} P r e s c r i b e d ~ D r u g}$ Register. ${ }^{\mathrm{C} T}$ Topical treatment: calcipotriol or calcipotriol combinations. ${ }^{\mathrm{d}}$ Non-biological systemic treatment: methotrexate,

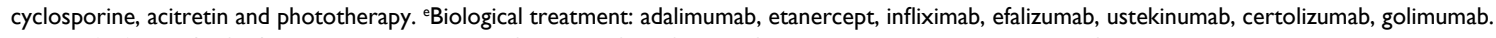

Abbreviations: ATC, Anatomical Therapeutic Chemical Classification System; BMI, body mass index; CVD, cardiovascular diseases; DM, diabetes mellitus; HTN, hypertension; IQR, interquartile range; MD, metabolic disease; MI, myocardial infarction; NPR, National Patient Register; PASI, psoriasis area and surface index; PDR, Prescribed Drug Register.

\section{References}

1. Bremander A, Jacobsson LT, Bergman S, Haglund E, Lofvendahl S, Petersson IF. Smoking is associated with a worse self-reported health status in patients with psoriatic arthritis: data from a Swedish populationbased cohort. Clin Rheumatol. 2015;34(3):579-583.

2. Kristensen LE, Jorgensen TS, Christensen R, et al. Societal costs and patients' experience of health inequities before and after diagnosis of psoriatic arthritis: a Danish cohort study. Ann Rheum Dis. 2017;76(9):1495-1501.
3. Ludvigsson JF, Lindelof B, Zingone F, Ciacci C. Psoriasis in a nationwide cohort study of patients with celiac disease. JInvest Dermatol. 2011;131(10): 2010-2016.

4. Oh EH, Ro YS, Kim JE. Epidemiology and cardiovascular comorbidities in patients with psoriasis: A Korean nationwide population-based cohort study. J Dermatol. 2017;44(6):621-629. 
Clinical Epidemiology is an international, peer-reviewed, open access, online journal focusing on disease and drug epidemiology, identification of risk factors and screening procedures to develop optimal preventative initiatives and programs. Specific topics include: diagnosis, prognosis, treatment, screening, prevention, risk factor modification,

Submit your manuscript here: https://www.dovepress.com/clinical-epidemiology-journal
Dovepress

systematic reviews, risk and safety of medical interventions, epidemiology and biostatistical methods, and evaluation of guidelines, translational medicine, health policies and economic evaluations. The manuscript management system is completely online and includes a very quick and fair peer-review system, which is all easy to use. 